\title{
The Role of Gender Dynamics in the Relationship between Parental Maltreatment and Juvenile Theft in South Korea
}

\author{
Hyunhee Hong ${ }^{1}$, Yoonsun Han ${ }^{1, *}$ and Dong Hun Lee ${ }^{3}$ \\ ${ }^{1}$ Department of Child Psychology and Education, Sungkyunkwan University, Korea \\ ${ }^{2}$ Department of Education, Sungkyunkwan University, Korea
}

\begin{abstract}
Juvenile theft is the leading crime among adolescents in Korea and is a serious social concern. The present study is an examination of youth theft in the framework of general strain theory, which asserts that criminal behavior occurs as a response to various strains, such as parental abuse and neglect. To test the role of parent-youth gender dynamics in the relationship between parental strain and youth theft, the current study analyzed a community-based sample of youth offenders and non-offenders in Korea $(N=374)$ using multivariate logistic regression models with interaction terms. Paternal physical abuse and maternal neglect predicted greater youth involvement in theft behavior. Regarding parent-youth gender dynamics, there was no difference in the role of maternal or paternal maltreatment in predicting theft behavior in sons or daughters. The exception was fathers' neglect, in which daughters showed higher odds of theft engagement than did sons who experienced even greater paternal neglect. The findings underscored the distinct and detrimental role of parental maltreatment in adolescent theft. The results supported the need to reach out to parents in consideration of the youth's gender and provided important implications for guiding current social services in preventing juvenile theft in Korea.
\end{abstract}

Keywords: General strain theory, parental abuse and neglect, parent-youth gender dynamics.

Juvenile theft is a serious social concern in South Korea (Korea hereafter). In 2012, approximately 35\% of theft offenses in Korea were committed by youths under the age of 19 (The National Police Agency Statistics Announcement 2013). Theft is the leading juvenile offense in Korea, followed by violence $(22 \%)$, fraud (7\%), and assault (5.2\%) (Institute for Justice 2012). The large proportion of theft among youth, however, is a relatively recent phenomenon, as property crime has become more prevalent than violent crime only since the past decade in Korea. In 1998, for instance, violent crime $(51.2 \%)$ was greater than property crime (43.0\%) (Institute for Justice 1999). Additionally, from 2008 to 2012, youth's re-offending theft rate increased from $8.1 \%$ to $12 \%$, which represents a $40 \%$ surge (Ministry of Justice 2013). The rate of juvenile theft reoccurrence is strikingly high, considering that it is three times that of adults (approximately $4 \%$ in 2012). Theft is often perpetrated by particularly young people, with youth who are 15 years old and younger committing over one-third of juvenile theft (Korean Crime White Paper 2013). In addition to the youth aspect, juvenile theft is a particularly salient issue because of the higher probability of recurrence compared to other forms of offenses (Lee and Cho 2005). Furthermore, repeated theft is usually accompanied by various forms of violent

*Address correspondence to this author at the Department of Child Psychology and Education, Sungkyunkwan University, 25-2 Sungkyunkwan-ro, Jongno-gu, Seoul, 110-745, Korea; Tel: +82 (02) 760-0526;

E-mail: yoonsunhan@skku.edu crime, such as assault, bodily injury, and threat (Lee 2003).

At an institutional level, some of the reasons for recurrence of juvenile theft may include the design of the current legal system, which stigmatizes and labels youth offenders as criminals, thus depriving them of opportunities until adulthood. In other words, once labeled an offender, the life prospects of such youths may deteriorate because they may not participate in the common activities enjoyed by those who have not been associated with criminal activities (Lee 2003). At a more interpersonal level, one of the primary reasons why researchers, policy makers, and practitioners should pay attention to adolescent theft is related to the idea of life-course-persistent delinquency (Moffitt 1993). Moffitt argued that interaction between youths, especially those at high risk, and their negative environments, such as inadequate parenting, builds antisocial traits. If such negative interactions are chronic, the antisocial traits subsequently formed throughout childhood and adolescence may result in negative adult outcomes (Moffitt et al. 2002).

This study attempts to research and identify the risky environments-particularly those involving negative interaction between parents and adolescents-that predict theft among adolescents in Korea. First, the authors offer a theoretical introduction to general strain theory and its application to understanding juvenile delinquency. Then, we identify the distinct effects of parental physical abuse and neglect in relation to youth theft, as well as how parent- 
youth gender dynamics may come into play. All empirical analyses were based on a community sample of adolescents in Korea. Finally, we discuss the analytic results and their implications for designing effective intervention programs to help prevent occurrence and recurrence of juvenile theft.

\section{GENERAL STRAIN THEORY: LINKING PARENTAL MALTREATMENT AND JUVENILE DELINQUENCY}

A wealth of research has found that one important risk factor that predicts child and adolescent delinquency, such as theft, is parental maltreatment in the family environment (Lewis, Mallouh, and Webb 1989; Brezina 1998; Hollist, Hughes, and Schaible 2009). Certainly, this finding does not imply that all maltreated children and adolescents become delinquents, but researchers have demonstrated that a disproportionately large fraction of delinquents have experienced childhood maltreatment (Ryan and Testa 2005; Allwood and Widom 2013).

An important perspective that can explain the link between maltreatment and delinquent behavior among youths is general strain theory (Agnew 1992). According to general strain theory, strain arouses negative emotions such as anger, which is considered one of the most powerful emotions linked with delinquency, subsequently triggering criminal behavior in the coping process (Agnew 1992). Not all strains are the same, however. In fact, considering that anger motivates deviant behavior in dealing with strains, some strains tend toward criminal behavior more than others (Agnew 2001). Therefore, a detailed examination of the types of strains most strongly linked with delinquency traits is warranted for understanding theft predictors among adolescents.

Painful interpersonal experiences between parents and youths, such as parental abuse and neglect, can be a strong source of strain for triggering anger. Since parenting involves continuous and cumulative interaction between the parent and the youth over a long period of time, strain aroused by parents may be considered more harmful than one-time aversive events for youths. This idea was confirmed in a metaanalysis conducted by Hoeve and colleagues (2009), who reported that parenting behaviors in general were the strongest predictor of delinquent behaviors among young people. According to the general strain theory framework, youths may choose to engage in delinquent behavior when they are exposed to chronic strains, such as parental abuse and neglect, which are considered noxious stimuli that adolescents most likely wish to escape or avoid. Additionally, recognizing the painful gap between what they expect (i.e., affectionate parenting) and what they actually experience (i.e., harsh or apathetic parenting) from parental maltreatment may be another way that youths experience the strains that result in delinquent behavior.

Although physical abuse and neglect are both considered a subtype of parental maltreatment because they are equally harmful for youth, they clearly have different characteristics that result in distinct effects. The literature provides some empirical findings to support the idea that parental abuse and neglect are associated with distinct youth outcomes. Prino and Peyrot (1994) argued that neglected children are more likely to be inhibited, whereas physically abused children tend to show aggressive behavior. Ryan and colleagues (2013) posited that neglect has a major influence on delinquency recidivism because of lack of adequate supervision or the social bonds that prevent youth from reoffending. Further, Lansford and colleagues (2007) found that parental physical abuse influenced not only violent delinquent behavior but also academic failure and teen pregnancy. Similarly, Fagan (2005) found that physical abuse was significantly related to adolescent crime, regardless of criminal types. Although various studies have confirmed that responses to parental strain may lead to different results, the body of research using a single study to examine the distinct effects of physical abuse and neglect on the likelihood of committing theft is relatively small.

\section{GENDER AND RESPONSE TO STRAIN}

Prior research contends that physical abuse and neglect are both causes of strains; however, males and females do not have identical responses to these strains in terms of delinquent behaviors. Recent studies have argued that gender differences existing in response to strain (Broidy and Agnew, 1997; Herrera and McCloskey 2001, Diamantopoulou, Verhulst, and Ende 2011; Francis 2014). Differing gender responses to parental abuse or neglect may account for such variations in behavior. For example, boys tend to resort to offensive crime to deal with strain because they attribute the aversive treatment to others, leading them to respond with anger and aggression. By contrast, it has been found that girls are less likely to commit offensive crime as a way to deal with strain because they attribute the aversive treatment to themselves. 
This situation likewise leads to anger, but it may be accompanied with depression. In addition, girls tend to consider expressing anger externally as a risk to their valued relationships, so they are more resistant to criminal behavior. In contrast, boys tend to consider that expressing anger externally is masculine, thus aggravating boys' criminal behavior (Broidy and Agnew 1997).

Despite the aforementioned gender patterns in the response to strain, the empirical literature seems to show mixed findings concerning the role of youths' gender in explaining different responses to strain. For example, Arata et al. (2007) found that there was no significant relationship between gender and interaction with maltreatment, even though they examined several types of maltreatment. Conversely, Cullerton-Sen and colleagues (2008) discovered that maltreated girls showed relational aggression more than maltreated boys. Maschi et al. (2008) also found that maltreated boys exhibited externalizing behavior, whereas maltreated girls showed internalizing symptoms. The gender interaction between parents and youths may account for such inconsistency in the literature.

Considering the separate role of mothers and fathers in the parent-youth relationship is important, and because the roles of mothers and fathers are unique, the effect of their parenting practices should be evaluated differently (Stoltz, Barber, and Olsen 2005; Lee et al. 2012). Relatively few studies, however, have concentrated on the sex of the perpetrator in maltreatment. Of the few, Moretti and Craig (2013) showed that gender matches (i.e., mother-daughter dyad or father-son dyad) and mismatches (i.e., fatherdaughter dyad or mother-son dyad) between parents and youths have different effects, even if the mother or father administers the same type of maltreatment. For example, maternal abuse was related to depression in both sons and daughters, whereas paternal abuse was related to depression in sons only (Moretti and Craig, 2013). Russell and Saebel (1997) argued that in examining the interaction between parent and child, the sex of the parent and the offspring should be considered simultaneously because the two construct their relationship together. Therefore, the interaction of sons and mothers can be different from the interaction of sons and fathers, and the same is true for daughters. In another example, Domene and colleagues (2011) discovered that mother-son dyads were more likely to experience conflict in their conversations than motherdaughter dyads; mother-daughter dyads also had more open attitudes in conversation than mother-son dyads.
Similarly, Kerig et al. (1993) noted the differences between father-son and father-daughter dyads: fathers preferred that their daughters be positive and obedient, and that their sons be assertive. These prior studies demonstrate, with regard to juvenile theft, that it is important not only to examine the role of parental strain in the form of physical abuse and neglect but also to consider gender interaction between parents and youths.

Therefore, the current study uses a gender match/mismatch framework to examine the role of parental-both maternal and paternal-abuse and neglect, and youth gender to understand juvenile theft. In this article, a gender-matched condition indicates that the sex of parent and youth is the same (e.g., mother-daughter dyad and father-son dyad). A gendermismatched condition indicates a sex difference between parent and youth (e.g., mother's parenting practices and son's behavior, father's parenting practices and daughter's behavior). Within this framework, the following research questions were developed.

(1) Does parental (father or mother) neglect increase theft?

(2) Does parental (father or mother) physical abuse increase theft?

(3) In a gender-matched condition, is parental neglect or physical abuse associated with youth theft?

(4) In a gender-mismatched condition, is parental neglect or physical abuse associated with youth theft?

Not only do the authors anticipate distinct roles in parental abuse and neglect for predicting youth theft, but the interaction between the sex of the maltreating parent and the receiving youth may also be an important factor. To confirm these hypotheses, we analyzed a community sample of adolescents in Korea.

\section{METHOD}

Data

A total of 374 youth participated in the study ( $N=$ 374; $M_{\text {male }}=82.7 \%, M_{\text {age }}=15.9$ years $)$. We analyzed a sample of youth offenders and non-youth offenders in middle and high schools in Korea. In detail, youth offenders were 10 to 19 year-olds who were arrested 
from March 2010 to December 2012 in a southern metropolitan area of Korea. Instead of being sent to juvenile correction systems, these youth were referred by the police to participate in an alternative counseling program provided by the local youth counseling support center. To compare the characteristics of youth offenders with youth non-offenders, middle and high school students from a southern province in Korea were recruited to participate in the study. All youths filled out a questionnaire that contained information about their demographics and their psychosocial, family, and school characteristics. For the purpose of the current study focusing on theft, a subsample of youths $(n=240)$ arrested for theft was analyzed out of the 471 young persons who participated in the alternative counseling program. After omitting questionnaires with missing information on variables that were used for the study, 195 youth offenders and 179 matching youths remained to be analyzed.

\section{Measures}

\section{Demographic Characteristics}

Two demographic characteristics representing gender and age were included in the analytic model. Female youths were coded as 1 and males as 0. Youths of high school age were coded as 1 and those of middle school age as 0 .

\section{Parental Neglect and Abuse}

Huh's (1999) Parenting Scale was used for measuring parental neglect and abuse. The full parenting scale, comprising 40 items, measured parental attitudes affecting the emotional and behavioral problems of adolescents as based on the youths' self-reports. Exposure to maltreatment experiences from mothers and fathers was surveyed separately on a 4-point scale ranging from 1 (never) to 4 (most of the time or very often). The neglect scale was assessed with six items, including neglect of medical and emotional needs ( $\alpha=.83$ and $\alpha=.80$ for mothers and fathers, respectively). The abuse scale was assessed with five items, including hitting or corporal punishment that resulted in bruises and/or injury ( $\alpha=.90$ and $\alpha=.88$ for mothers and fathers, respectively).

\section{Peer Conformity}

Oh's (1990) scale was used to measure peer conformity. This scale consisted of 16 hypothetical situations-11 of which were chosen from Berndt's (1979) 20 questions, including antisocial and neutral behavior, which were appropriate for Korean children and adolescents' usual situations. The additional five questions, which were extracted from prior research, were considered adequate with respect to the sample's gender and age group. For each hypothetical situation, on a 6-point scale ranging from 1 (absolutely not following peers' tendency) to 6 (absolutely following peers' tendency), participants were asked what they would do when their wants conflicted with those of peers. Higher numbers indicated a greater level of peer conformity $(\alpha=.75)$. Neutral behaviors were measured by eight items, like joining peers' activities (e.g., "I went downtown with my best friends. All my friends wanted to have Chinese food for lunch, but I wanted to eat pizza instead. My friends urged me to go to the Chinese restaurant. In this situation, what would you do?"). Antisocial behaviors included eight items, such as shoplifting and cheating (e.g., "On my way home, there was a small grocery store. I could not see the storekeeper. Nobody was in sight. There were a lot of cookies on the store shelf near the street. All my best friends stole a cookie, but I did not want to. At that moment, my friends told me that I should also steal a cookie. In this situation, what would you do?").

\section{School Maladjustment}

A school resilience inventory was used to assess the degree to which youths adjusted to the school environment (Park 1998). This scale comprised a total of 22 questions concerning youths' interest in school, academic performance, and conformity to school norms and rules (e.g., "I think that going to school is just waste of my time."). All questions were formulated for response on a 4-point scale ranging from 1 (never) to 4 (most of the time or very often) $(\alpha=.92)$.

\section{Statistical Analysis}

A descriptive summary of demographic, parenting, peer, and school variables used in the study was first presented. Then multivariate logistic regression models with interaction terms were used to test whether parental maltreatment in relation to youth gender predicted juvenile theft behavior.

\section{RESULTS}

\section{Descriptive Statistics}

A descriptive summary of main variables used in the study is presented in Table 1 . The majority of the sample was male (84\%). Most study participants fell toward the upper age limit $(70 \%$ in high school). 
Table 1: Descriptive Summary $(\mathrm{N}=374)$

\begin{tabular}{|c|c|c|c|c|c|}
\hline Variable & Mean (\%) & Standard Deviation & Min & Max & Alpha \\
\hline Female & $16 \%$ & - & - & - & - \\
\hline School grade & $70 \%$ & - & - & - & - \\
\hline Mother neglect & 1.85 & 0.83 & 1 & 4.6 & 0.83 \\
\hline Father neglect & 2.06 & 0.78 & 1 & 4.4 & 0.80 \\
\hline Mother abuse & 1.70 & 0.82 & 1 & 5 & 0.90 \\
\hline Father abuse & 1.90 & 0.91 & 1 & 5 & 0.88 \\
\hline Peer conformity & 3.41 & 0.67 & 1 & 5.5 & 0.75 \\
\hline School maladjustment & 2.19 & 0.57 & 1 & 4 & 0.92 \\
\hline
\end{tabular}

Participants reported slightly more experiences of paternal abuse and neglect compared to maternal maltreatment. Average peer conformity score was 3.41 $(S D=0.66)$, indicating moderate levels of peer conformity. Study participants showed relatively low levels of school adjustment, with an average score of $2.19(S D=0.57)$.

\section{Paternal Neglect versus Maternal Neglect}

Table 2 shows the results of models that tested whether parental neglect (by either mother or father) increased theft. Models 2 and 3 present the results of the interaction models that indicated gender-matched and gender-mismatched conditions, respectively. In these models, maternal neglect was a significant predictor of theft, whereas paternal neglect was not.

Table 2: Parental Neglect and Adolescent Theft Behavior (Reported in Odds Ratios; $\mathbf{N}=374$ )

\begin{tabular}{|c|c|c|c|}
\hline Variables & Model (1) & Model (2) & Model (3) \\
\hline \multicolumn{4}{|l|}{ Main variables } \\
\hline \multirow[t]{2}{*}{ Female $^{a}$} & $1.97+$ & 1.41 & 0.19 \\
\hline & $(0.70)$ & (1.34) & $(0.22)$ \\
\hline \multirow[t]{2}{*}{ Father neglect $^{a}$} & 0.81 & 0.81 & $0.68+$ \\
\hline & $(0.16)$ & $(0.16)$ & $(0.14)$ \\
\hline \multirow[t]{2}{*}{ Mother neglect } & $1.72^{* *}$ & $1.68^{* *}$ & $1.82^{* *}$ \\
\hline & $(0.32)$ & $(0.33)$ & $(0.35)$ \\
\hline \multirow[t]{2}{*}{ Female X Mother neglect } & & 1.21 & \\
\hline & & $(0.60)$ & \\
\hline \multirow[t]{2}{*}{ Female $X$ Father neglect } & & & $3.40^{*}$ \\
\hline & & & (1.93) \\
\hline \multicolumn{4}{|l|}{ Control variables } \\
\hline \multirow[t]{2}{*}{ School grade ${ }^{b}$} & $4.04^{* * *}$ & $4.00^{\star * *}$ & $3.88^{* * *}$ \\
\hline & $(1.16)$ & $(1.15)$ & $(1.13)$ \\
\hline \multirow[t]{2}{*}{ Peer conformity } & 0.84 & 0.84 & 0.83 \\
\hline & $(0.17)$ & $(0.17)$ & $(0.17)$ \\
\hline \multirow[t]{2}{*}{ School maladjustment } & $3.97^{* * *}$ & $3.98^{* * *}$ & $4.09^{\star \star *}$ \\
\hline & (1.09) & (1.09) & (1.13) \\
\hline \multirow[t]{2}{*}{ Constant } & $0.02^{* * *}$ & $0.02^{* * *}$ & $0.03^{* * *}$ \\
\hline & $(0.02)$ & $(0.02)$ & $(0.02)$ \\
\hline
\end{tabular}

Note: Standard errors in parentheses; ${ }^{* * *} p<0.001,{ }^{* *} p<0.01,{ }^{*} p<0.05,+p<0.1$.

${ }^{\mathrm{a}} \mathrm{Female}=1$, Male $=0 ;{ }^{\mathrm{b}} \mathrm{High}$ school $=1$, Middle school $=0$. 
Table 3: Parental Abuse and Adolescent Theft Behavior (Reported in Odds Ratios; $\mathbf{N}=374$ )

\begin{tabular}{|c|c|c|c|}
\hline \multicolumn{4}{|l|}{ Main variables } \\
\hline Female $^{a}$ & $(0.80)$ & $(1.47)$ & $(0.62)$ \\
\hline Father abuse ${ }^{a}$ & $1.60^{\star *}$ & $1.60^{* *}$ & $1.46^{*}$ \\
\hline \multirow[t]{2}{*}{ Mother abuse } & $1.39+$ & 1.36 & 1.39 \\
\hline & $(0.28)$ & $(0.28)$ & $(0.28)$ \\
\hline \multirow[t]{2}{*}{ Female X Mother abuse } & & 1.16 & \\
\hline & & $(0.56)$ & \\
\hline \multirow[t]{2}{*}{ School grade ${ }^{b}$} & $4.48^{* * *}$ & $4.48^{* * *}$ & $4.43^{* * *}$ \\
\hline & $(1.34)$ & $(1.34)$ & $(1.33)$ \\
\hline \multirow[t]{2}{*}{ Peer conformity } & 0.88 & 0.88 & 0.88 \\
\hline & $(0.18)$ & $(0.18)$ & $(0.18)$ \\
\hline \multirow[t]{2}{*}{ School maladjustment } & $3.30^{* * *}$ & $3.29^{\star \star \star}$ & $3.26^{\star \star *}$ \\
\hline & $(0.87)$ & $(0.87)$ & $(0.86)$ \\
\hline \multirow[t]{2}{*}{ Constant } & $0.01^{* * *}$ & $0.01^{* \star *}$ & $0.01^{* * *}$ \\
\hline & $(0.01)$ & $(0.01)$ & $(0.01)$ \\
\hline
\end{tabular}

Note: Standard errors in parentheses; ${ }^{* *} p<0.001,{ }^{* *} p<0.01,{ }^{*} p<0.05,+p<0.1$.

${ }^{\mathrm{a}}$ Female $=1$, Male $=0 ;{ }^{\mathrm{b}}$ High school $=1$, Middle school $=0$.

Increased levels of mothers' neglect increased youths' odds of theft $(O R=1.72, p<.01$ in Model $1 ; O R=$ $1.68, p<.01$ in Model $2 ; O R=1.82, p<.01$ in Model $3)$. Conversely, there was no statistically significant association between changes in fathers' neglect and theft involvement. In terms of gender-matched conditions, the mother-daughter neglect interaction was not statistically significant. The father-daughter neglect interaction term that represented gender mismatch, however, was significant $(O R=3.40, p<.05)$. In other words, female youths experienced increased odds of theft engagement over male youths with increased levels of paternal neglect.

\section{Paternal Abuse Versus Maternal Abuse}

The role of abuse in predicting juvenile theft is represented in Table 3. Paternal physical abuse was a significant predictor of theft, whereas maternal physical abuse was not. Increased levels of fathers' abuse increased youths' odds of committing theft $(O R=1.60$, $\mathrm{p}<.01$ in Model 4; OR = 1.60 in Model 5, p $<0.01$; and $O R=1.46, p<0.05$ in Model 6$)$. On the other hand, there was no statistically significant association between changes in mothers' abuse and theft involvement. Additionally, there were no significant interaction effects for parental abuse in the case of both gender-matched and gender-mismatched conditions.

\section{DISCUSSION}

The aim of this study was to examine the critical factors associated with juvenile theft in Korea. Based on the general strain theory, the authors anticipated that different types of parental strain, represented as physical abuse and neglect, would each have unique relationships with juvenile theft behavior. Additionally, we conjectured that males and females would have different gendered responses to these parental strains. Consequently, we expected that gender-match and gender-mismatch conditions would play a critical role in predicting theft behavior, as well. Although not all of our initial hypotheses were confirmed, we were able to draw important conclusions from the analytic results, particularly pertaining to the distinct role of mothers and 
fathers and the gender dynamics involved in predicting youth theft. A detailed discussion of our findings is presented here.

Typically, fathers are more likely to be neglectful parents than are mothers (Panetta et al. 2014). This finding was also identified in the current sample of Korean young people. In terms of relationship with theft behavior, however, maternal neglect significantly predicted youth theft, whereas paternal neglect did not. One plausible explanation for this observation may relate to the fact that the mother is more likely than the father to be considered the primary caregiver in a variety of contexts (Moon and Hoffman 2008), Korea being no exception (Lee et al. 2012). Parental neglect, which is a deficit in or failure of meeting youths' needs may induce frustration among adolescents. General strain theory theorists who argue that adverse relationships can lead to delinquency (Agnew 1992) suggest that absence of adequate care from the primary caregiver may have a more prominent negative effect on theft engagement than neglectful parenting by the secondary caregiver, as youth frustration is aggravated if adequate care is not received from the primary caregiver, which in this case is the mother.

Another important finding of the current study was that paternal abuse significantly predicted youth theft, whereas maternal abuse did not. The mother is often considered the instructor in the family (Russell and Russell 1987), who directs the offspring's appropriate behavior-for example, washing hands or being polite. Because of this role, unlike when abusive parenting practices come from the father, both sons and daughters may consider maternal physical abuse as "discipline" rather than "abuse," thus possibly explaining why it plays a smaller detrimental role with regard to youth theft. Wu and colleagues (2014) confirmed this idea by reporting that regardless of the offspring's gender, fathers' hostility was related to an increase in juvenile delinquency, but mothers' was not.

Finally, among all interaction terms indicating gender-matched and mismatched conditions, only the father-daughter neglect interaction term was significantly related to theft. In other words, there was almost no difference in the role of maternal or paternal maltreatment in predicting theft by either sons or daughters. The exception was fathers' neglect, in which daughters showed increased odds of theft engagement than did sons who experienced even greater paternal neglect. One possible explanation for this finding may be that parents establish gender stereotypes and different expectations for sons and daughters, and, subsequently, have different parental perceptions of appropriate parenting behavior for the mother and father (Moon and Hoffman 2008). For example, Russell and Russell (1987) contended that parents expect greater independence for sons than for daughters. This expectation can be transmitted to young people, such that sons perceive paternal negligence as encouraging independence, whereas daughters may be more sensitive to the absence of fathers' care giving, perhaps perceiving paternal neglect as lack of care. In this case, girls are more likely to attribute aversive treatment to their fathers than are boys, leading to anger and eventual delinquent behavior. However, a detailed examination of the exact mechanisms that come into play is warranted in future research regarding parent-youth gendered dynamics for understanding youth delinquent behavior.

Despite the important findings of this study, the results must be interpreted with care in consideration of the following limitations. First, the results of this study may not be applicable to other populations, as the study participants were not identified based on equal probability sampling. The youth participants with theft experience and general youths without any theft experience analyzed in the current study were from a community-based sample in a southern part of Korea, which limits extending study findings to a different population. Further research with a broader range of samples may provide a more generalizable association between maltreatment and the gender conditions. Second, without use of longitudinal data, it is difficult to make a causal statement that parental abuse and neglect lead to increased chance of juvenile theft. A reversed situation may also be possible in which youths' antisocial behavior induces parental behaviors that are more abusive or neglectful (Anderson, Lytton, and Romney 1986; Moffit, 1993). In addition, consideration of temperament may be important for understanding predictors of youth theft, as prior work has confirmed that temperament strongly predicts adolescent outcomes (Day and Padilla-Walker 2009; Panetta et al. 2014). Furthermore, consideration of how parenting behaviors may be modified owing to youth temperament and interaction over time may also be important. Finally, the results of the current study may be limited because indicators of parental behavior were measured by the youths' self-report. Although youthreported measures are considered a valid source of information (Stolz et al. 2005), it is possible that youth evaluations of parental behaviors would differ from the 
parents' own perception of their behavior, as shown by the low correlation between youth-reported and parentreported measures of parenting in some previous studies (Han et al. 2012).

Notwithstanding these limitations, our study may shed light on several areas. The current study examined the role of parental abuse and neglect within the general strain theory framework to predict adolescent involvement in theft. Consideration of both parental abuse and neglect-particularly neglect, because this aspect needs more research (Maughan and Moore 2010)—may highlight that these two subtypes of maltreatment have unique associations with youth theft. Not only did this study use parenting behaviors of both mother and father, but also it identified the unique contribution of one parent's behavior while controlling for the other's behavior in predicting youth theft. In particular, examining the role of fathers contributes to broadening our understanding of the distinct role of mothers and fathers, especially when the paternal role has been relatively less examined (Panetta et al. 2014). This study also extended a relatively nascent research area that examines the gender dynamics of parent and offspring in understanding youth outcomes (Day and PadillaWalker 2009).

In sum, adolescence is an especially capricious period during which youths face emotional and physical changes as they enter adulthood. Accordingly, parental abuse and neglect in adolescence may be more harmful than in childhood, considering juveniles' developmental tasks (Williamson, Borduin, and Howe 1991). The current study, which highlighted the damaging role of abusive and neglectful behaviors of mothers and fathers in increasing the probability of youth theft, used a rare sample of vulnerable Korean youth. The findings underscored the need to reach out to parents in consideration of the youths' gender, and it may have important implications for guiding current counseling services in Korea, which focus primarily on treating only juvenile offenders.

\section{REFERENCES}

Agnew, Robert. 1992. "Foundation for a General Strain Theory of Crime and Delinquency." Criminology 30(1):47-88. http://dx.doi.org/10.1111/j.1745-9125.1992.tb01093.x

-----. 2001. "Building on the Foundation of General Strain Theory: Specifying the Types of Strain most Likely to Lead to Crime and Delinquency." Journal of Research in Crime and Delinquency 38(4):319-361.

http://dx.doi.org/10.1177/0022427801038004001
Allwood, Maureen A. and Cathy S. Widom. 2013. "Child Abuse and Neglect, Developmental Role Attainment, and Adult Arrests." Journal of Research in Crime and Delinquency 50(4):551578.

http://dx.doi.org/10.1177/0022427812471177

Anderson, Kathleen E., Hugh Lytton and David M. Romney. 1986. "Mothers' Interactions with Normal and Conduct-Disordered Boys: Who Affects Whom?" Developmental Psychology 22(5):604-609.

http://dx.doi.org/10.1037/0012-1649.22.5.604

Arata, Catalina M., Jennifer Langhinrichsen-Rohling, David Bowers and Natalie O'Brien. 2007. "Differential Correlates of MultiType Maltreatment among Urban Youth." Child Abuse \& Neglect 31(4):393-415. http://dx.doi.org/10.1016/j.chiabu.2006.09.006

Berndt, Thomas J. 1979. "Developmental Changes in Conformity to Peers and Parents." Developmental Psychology 15(6):608616.

http://dx.doi.org/10.1037/0012-1649.15.6.608

Brezina, Timothy. 1998. "Adolescent Maltreatment and Delinquency: The Question of Intervening Processes." Journal of Research in Crime and Delinquency 35(1):71-99. http://dx.doi.org/10.1177/0022427898035001003

Broidy, Lisa and Robert Agnew. 1997. "Gender and Crime: A General Strain Theory Perspective." Journal of Research in Crime and Delinquency 34(3):275-306. http://dx.doi.org/10.1177/0022427897034003001

Cullerton-Sen, Crystal, Adam R. Cassidy, Dianna Murray-Close, Dante Cicchetti, Nicki R. Crick and Fred A. Rogosch. 2008. "Childhood Maltreatment and the Development of Relational and Physical Aggression: The Importance of a Gender-Informed Approach." Child Development 79(6):17361751. http://dx.doi.org/10.1111/j.1467-8624.2008.01222.x

Day, Randal D. and Laura M. Padilla-Walker. 2009. "Mother and Father Connectedness and Involvement during Early Adolescence." Journal of Family Psychology 23(6):900-904. http://dx.doi.org/10.1037/a0016438

Diamantopoulou, Sofia, Frank C. Verhulst and Jan van der Ende. 2011. "Gender Differences in the Development and Adult Outcome of Co-Occurring Depression and Delinquency in Adolescence." Journal of Abnormal Psychology 120(3):644655.

http://dx.doi.org/10.1037/a0023669

Domene, José F., Krista D. Socholotiuk and Richard A. Young. 2011. "The Early Stages of the Transition to Adulthood: Similarities and Differences between Mother-Daughter and Mother-Son Dyads." Qualitative Research in Psychology 8(3):273-291. http://dx.doi.org/10.1080/14780880903568022

Fagan, Abigail A. 2005. "The Relationship between Adolescent Physical Abuse and Criminal Offending: Support for an Enduring and Generalized Cycle of Violence." Journal of Family Violence 20(5):279-290. http://dx.doi.org/10.1007/s10896-005-6604-7

Francis, Kimberly A. 2014. "General Strain Theory, Gender, and the Conditioning Influence of Negative Internalizing Emotions on Youth Risk Behaviors." Youth Violence and Juvenile Justice 12(1):58-76.

http://dx.doi.org/10.1177/1541204013477428

Han, Yoonsun, Andrew Grogan-Kaylor, Cristina Bares, Julie Ma, Marcela Castillo and Jorge Delva. 2012. "Relationship between Discordance in Parental Monitoring and Behavioral Problems among Chilean Adolescents." Children and Youth Services Review 34(4):783-789. http://dx.doi.org/10.1016/j.childyouth.2012.01.005

Hankin, Benjamin L., Lyn Y. Abramson, Terrie E. Moffitt, Phil A. Silva, Rob McGee and Kathryn E. Angell. 1998. "Development of Depression from Preadolescence to Young 
Adulthood: Emerging Gender Differences in a 10-Year Longitudinal Study." Journal of Abnormal Psychology 107(1):128-140.

http://dx.doi.org/10.1037/0021-843X.107.1.128

Hendy, Helen M., Kristen Weiner, John Bakerofskie, Doreen Eggen, Cheryl Gustitus and Kelli C. McLeod. 2003. "Comparison of Six Models for Violent Romantic Relationships in College Men and Women." Journal of Interpersonal Violence 18(6):645-665.

http://dx.doi.org/10.1177/0886260503251180

Herrera, Veronica M. and Laura A. McCloskey. 2001. "Gender Differences in the Risk for Delinquency among Youth Exposed to Family Violence." Child Abuse \& Neglect 25(8):1037-1051. http://dx.doi.org/10.1016/S0145-2134(01)00255-1

Hoeve, Machteld, Judith S. Dubas, Veroni I. Eichelsheim, van der Laan, Peter H, Wilma Smeenk and Jan R. Gerris. 2009. "The Relationship between Parenting and Delinquency: A MetaAnalysis." Journal of Abnormal Child Psychology 37(6):749775.

http://dx.doi.org/10.1007/s10802-009-9310-8

Hollist, Dusten R., Lorine A. Hughes and Lonnie M. Schaible. 2009. "Adolescent Maltreatment, Negative Emotion, and Delinquency: An Assessment of General Strain Theory and Family-Based Strain." Journal of Criminal Justice 37(4):379387.

http://dx.doi.org/10.1016/j.jcrimjus.2009.06.005

Huh, MyoYeon. 1999. "The Study for the Development and Validation of "parenting Behavior inventory perceived by Adolescent." PhD dissertation, Department of Psychology, Ewha Womans University, Seoul, Korea.

Institute of Justice. (1999). Criminal Justice Statistics in Korea: The White Paper on Crime 1999 [1999범죄백서]. Legal Research \& Training Institute, Ministry of Justice, Republic of Korea Retrieved from https:// http://www.ioj.go.kr/homepage/ information/DataAction. do? method=view.

-----. (2012). Criminal Justice Statistics in Korea: The White Paper on Crime 2012 [2012 범죄백서]. Legal Research \& Training Institute, Ministry of Justice, Republic of Korea Retrieved from https://www.Irti.go.kr/homepage/information/Data Action.do?method=view.

Kurtz, P. D., James M. Gaudin, Phyllis T. Howing and John S. Wodarski. 1993. "The Consequences of Physical Abuse and Neglect on the School Age Child: Mediating Factors." Children and Youth Services Review 15(2):85-104. http://dx.doi.org/10.1016/0190-7409(93)90038-B

Lansford, J. E., S. Miller-Johnson, L. J. Berlin, K. A. Dodge, J. E. Bates and G. S. Pettit. 2007. "Early Physical Abuse and Later Violent Delinquency: A Prospective Longitudinal Study." Child Maltreatment 12(3):233-245. http://dx.doi.org/10.1177/1077559507301841

Lee, Dong Won. 2003. "A Study on Juvenile Recidivism." Korean Journal of Criminology 15(2): 358-359.

Lee, Jae Rim, Ji Ae Kim, Yoon Joo Lee, and Yoon A Chin. 2012. "A Meta-analytic Study of Associations between Father Involvement and Children's Developmental Characteristics." Journal of Family Relations 17(1):151-173.

Lee, Soo Jung and Eun Kyung Cho.2005."Development of a Risk Assessment Tool for Juveniles at Police Investigation." Korean Journal of Counseling and Psychotherapy 19(1):2743.

Maschi, Tina, Keith Morgen, Carolyn Bradley and Schnavia S. Hatcher. 2008. "Exploring Gender Differences on Internalizing and Externalizing Behavior among Maltreated Youth: Implications for Social Work Action." Child and Adolescent Social Work Journal 25(6):531-547. http://dx.doi.org/10.1007/s10560-008-0139-8
Maughan, Daniel and Simon C. Moore. 2010. "Dimensions of Child Neglect: An Exploration of Parental Neglect and its Relationship with Delinquency." Child Welfare 89(4):47-65.

Ministry of Justice. 2013. Crime Prevention Policy Bureau Statistics, Ministry of Justice, Republic of Korea. Retrieved from http://www.index.go.kr/potal/main/EachDtIPageDetail.do?idx $\mathrm{cd}=1736$.

Moffitt, Terrie E. 1993. "Adolescence-Limited and Life-CoursePersistent Antisocial Behavior: A Developmental Taxonomy." Psychological Review 100(4):674-701. http://dx.doi.org/10.1037/0033-295X.100.4.674

Moffitt, Terrie E., Avshalom Caspi, Honalee Harrington and Barry J. Milne. 2002. "Males on the Life-Course-Persistent and Adolescence-Limited Antisocial Pathways: Follow-Up at Age 26 Years." Development and Psychopathology 14(01):179207.

http://dx.doi.org/10.1017/S0954579402001104

Moon, Michelle and Charles D. Hoffman. 2008. "Mothers' and Fathers' Differential Expectancies and Behaviors: Parent $\mathrm{x}$ Child Gender Effects." The Journal of Genetic Psychology 169(3):261-280.

http://dx.doi.org/10.3200/GNTP.169.3.261-280

Moretti, Marlene M. and Stephanie G. Craig. 2013. "Maternal Versus Paternal Physical and Emotional Abuse, Affect Regulation and Risk for Depression from Adolescence to Early Adulthood." Child Abuse \& Neglect 37(1):4-13. http://dx.doi.org/10.1016/j.chiabu.2012.09.015

Oh, Kyung Hee. 1990. "A study on the peer conformity development of child." A Master's Thesis. Department of Child Study, Sookmyung Women's University, Seoul, Korea.

Panetta, Shannon M., Cheryl L. Somers, Ashley R. Ceresnie, Stephen B. Hillman and Robert T. Partridge. 2014. "Maternal and Paternal Parenting Style Patterns and Adolescent Emotional and Behavioral Outcomes." Marriage \& Family Review 50(4):342-359. http://dx.doi.org/10.1080/01494929.2013.879557

Park, Hyun Sun. 1998. "The Impact of Risk Factors and Protective Factors on the School Resilience of Korean Adolescents in Poverty." Korean Journal of Social Welfare Studies 11:23-52.

Prino, Claudia T. and Mark Peyrot. 1994. "The Effect of Child Physical Abuse and Neglect on Aggressive, Withdrawn, and Prosocial Behavior." Child Abuse \& Neglect 18(10):871-884. http://dx.doi.org/10.1016/0145-2134(94)90066-3

Russell, Alan and Judith Saebel. 1997. "Mother-son, motherdaughter, father-son, and father-daughter: Are they Distinct Relationships?" Developmental Review 17(2):111-147. http://dx.doi.org/10.1006/drev.1996.0431

Russell, Graeme and Alan Russell. 1987. "Mother-Child and FatherChild Relationships in Middle Childhood." Child Development 58(6):1573-1585. http://dx.doi.org/10.2307/1130696

Ryan, Joseph P. and Mark F. Testa. 2005. "Child Maltreatment and Juvenile Delinquency: Investigating the Role of Placement and Placement Instability." Children and Youth Services Review 27(3):227-249. http://dx.doi.org/10.1016/j.childyouth.2004.05.007

Ryan, Joseph P., Abigail B. Williams and Mark E. Courtney. 2013. "Adolescent Neglect, Juvenile Delinquency and the Risk of Recidivism." Journal of Youth and Adolescence 42(3):454465. http://dx.doi.org/10.1007/s10964-013-9906-8

Stolz, Heidi E., Brian K. Barber and Joseph A. Olsen. 2005. "Toward Disentangling Fathering and Mothering: An Assessment of Relative Importance." Journal of Marriage and Family 67(4):1076-1092. http://dx.doi.org/10.1111/j.1741-3737.2005.00195.x

Williamson, Jeffrey M., Charles M. Borduin and Barbara A. Howe. 1991. "The Ecology of Adolescent Maltreatment: A Multilevel 
Examination of Adolescent Physical Abuse, Sexual Abuse, and Neglect." Journal of Consulting and Clinical Psychology 59(3):449-457.

http://dx.doi.org/10.1037/0022-006X.59.3.449

Wu, Ed Y., Ben T. Reeb, Monica J. Martin, Frederick X. Gibbons, Ronald L. Simons and Rand D. Conger. 2014. "Paternal
Hostility and Maternal Hostility in European American and African American Families." Journal of Marriage and Family 76(3):638-651.

http://dx.doi.org/10.1111/jomf.12107

Received on 01-09-2014 Accepted on 17-09-2014

Published on 24-10-2014

DOI: http://dx.doi.org/10.6000/1929-4409.2014.03.26

(c) 2014 Hong et al.; Licensee Lifescience Global.

This is an open access article licensed under the terms of the Creative Commons Attribution Non-Commercial License (http://creativecommons.org/licenses/by-nc/3.0/) which permits unrestricted, non-commercial use, distribution and reproduction in any medium, provided the work is properly cited. 